\title{
Interpretation of Magnetic Data for the Determination of Geological Structures in Southern Part of the Cuvette-Centrale Sedimentary Basin
}

\section{Tondozi Keto $^{1}$, Stanislas Maneno Saidi ${ }^{2}$, Serge Kambale Bahati ${ }^{3}$, Joseph Munezero Ntibahanana ${ }^{4}$ \& Jonathan Matadi Ndombasi ${ }^{5}$}

\author{
Professor ${ }^{1}$
}

Department of Physics, Faculty of Sciences, University of Kinshasa

Kinshasa, Democratic Republic of Congo,

Research Scholar 2345

Geophysical Research Centre (C.R.G), Kinshasa, Democratic Republic of Congo, Research Scholar ${ }^{4}$

Department of Exploration and Production, Faculty of Oil, Gas and New Energies, University of Kinshasa

Kinshasa, Democratic Republic of Congo,

Research Scholar ${ }^{4}$

Department of Geophysics, School of Geosciences, China University of Petroleum (East-China)

Qingdao, People's Republic of China

\begin{abstract}
The Democratic Republic of Congo is willing to develop its natural underground resources in sight to increase its economy. To this end, the oil and gas potential of its sedimentary basins is now the new target. Into the Cuvette-centrale sedimentary basin several exploration works were carried out since 1950s. Among these works we have the magnetic survey done in 1980 year which provided us the data used in this paper. The source rocks as well as the potential reservoir rocks and some oil seeps that have been recognized in this gigantic basin encourage researchers to find favorable geological structures for the accumulation of hydrocarbons in this sedimentary basin. Indeed, it is for this purpose that we have been interested to determine the regional geological structures in the southern part of this basin from magnetic data. After analysis, processing, and interpretation of the data, it found that the Kutu, Oshwe, Bagata, Bulungu and Idiofa areas contain geological structures contributing to the confirmation of the existence of an active petroleum system. Concretely, on one hand and from the shape of the crystalline basement we arrived to determine several faults and folds that can be taken as the excellent hydrocarbon traps and on the other hand, ditches that are privileged and favorable environments for the maturation of source rocks.
\end{abstract}

Key Words: Magnetic Survey, Source Rocks, Oil Seeps, Faults, Folds, Interpretation.

\section{INTRODUCTION}

The Cuvette-centrale sedimentary Basin is one of the three great sedementary basins of the Democratic Republic of Congo, which has undergone the extensional movement from the Upper Cambrian to the Terrestrial (from Hercynian tectonic phase to the Upper Devonian, Permo-carboniferous and Triassic). The basin is a favorable area to meet geological structures of capital interest in oil exploration. Several levels of sedimentary geological assemblages imply the possibility of the existence of mature source rocks; reservoir rocks and potential cover rocks. Confirmation of oil seeps along the Lukeni River and Mai-Ndombe Lake supports the hypothesis of a complete petroleum system in this sedimentary basin.

\section{LOCATION OF THE STUDY AREA}

Our study area is located in the South-west of the Democratic Republic of Congo, in the former province of Bandundu. It extends between 18 and 20 degrees East of longitude and 3 and 4 degrees,50 minutes South of latitude with an area of approximately $40,000 \mathrm{Km}^{2}$ (Figure 1). This area of study covers the following six territories: Kutu, Oshwe, Bagata, Bulungu, Idiofa. 


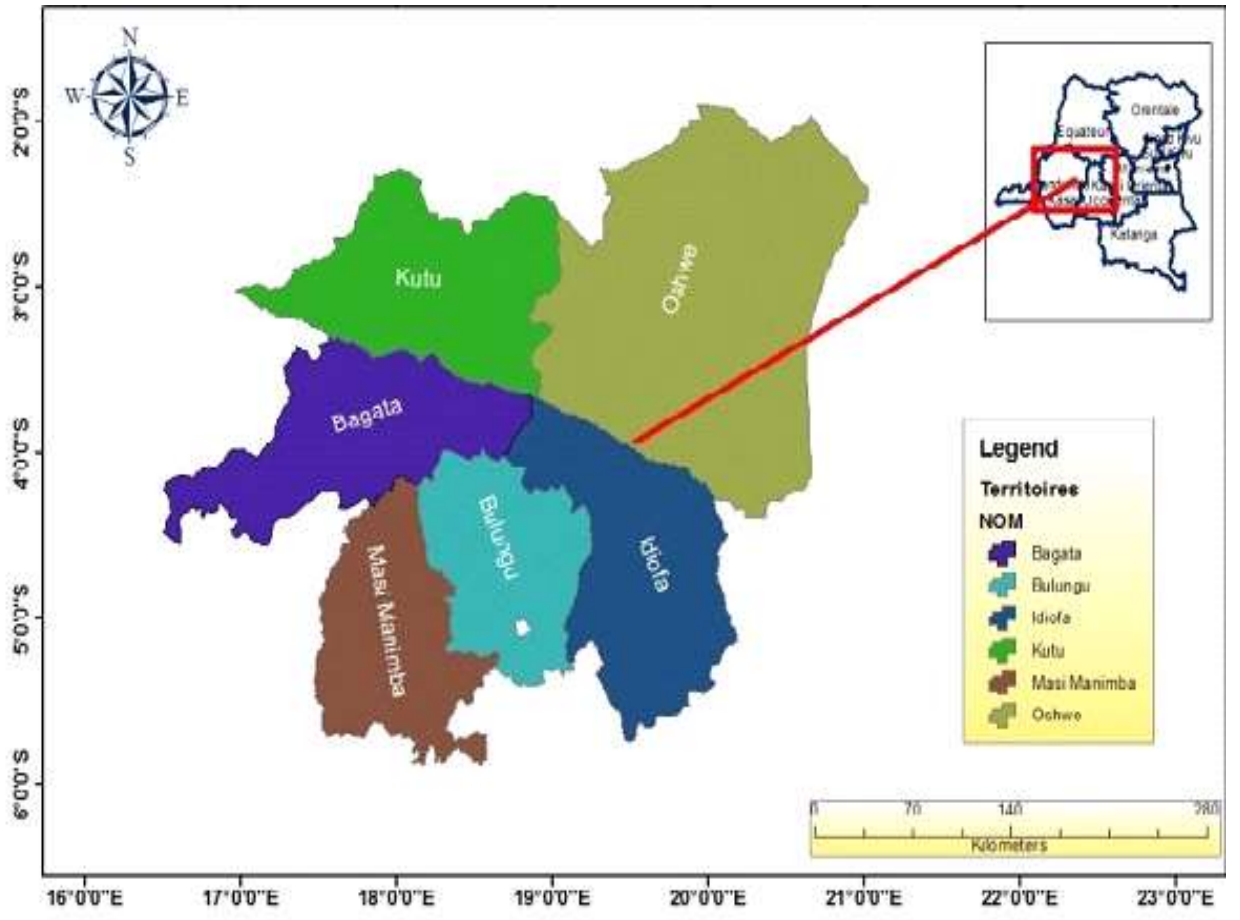

Figure1. Location map of the study area

\section{METHOD AND MATERIAL USED}

\subsection{Method: Magnetic prospecting}

The magnetic prospecting method is based on the study of anomalies of the magnetic field. These anomalies derive their sources from the magnetic properties of the different rocks of the earth's crust; hence this method is one of the techniques applied in the hydrocarbon exploration that we have used. It is possible to determine the shape of the crystalline basement and the faults undergone by the Earth's magnetic field.

The analysis of the shape of the bedrock as well as faults is important in petroleum exploration because it allows to locate deep areas that play major roles for the maturation of the potential source rocks because of the variation of temperature and pressure in relationship with the increasing of the depth. These areas are called Leads. Faults highlighted after the interpretation of the magnetic maps can be considered as structural traps as they can trap and accumulate hydrocarbons [1]. Magnetic prospecting aims to study the ambient magnetic field which is a combination of the solar magnetic field, the Earth's magnetic field, magnetic rocks and anthropogenic induction value (in Tesla). In general, variations in the induction are of the order of a few tens of nT, example between 20,000 and 60,000 nT and the average value of the ambient field is of the order of 47,000 nT. This is why it is asked to check if the magnetometer is calibrated for the average value of the magnetic field of the workplace. There are two types of magnetization:

- Induced magnetization: which is a magnetization directly proportional to the magnetic susceptibility of the materials to be magnetized under the action of a magnetic excitation and;

- The remnant magnetization: strong magnetization remaining even after the disappearance of the external magnetic field.

In magnetic prospecting, magnetic susceptibility is a fundamental parameter, since the magnetic response of rocks itself. Therefore, the purpose of magnetic prospecting is to collect data concerning the magnetic field of the entire globe, continent or country, in condensed form. The magnetic field vector measured on the surface of the earth, in the air or in space, is formed of three components anomaly:

\subsubsection{The main field}

Its origin is in the Earth's care. Since the measurements are made at a distance of about 3,000 km from the surface of the nucleus, this part of the magnetic field appears as a regular function of latitude and longitude. The description of the main field that varies slowly over time (secular variation) is one of the fundamental goals of magnetic prospecting.

\subsubsection{The field of the earth's crust}

It is a regularly superimposed on the main field and comes from the earth's crust, probably from its outer part, which is 18 to 25 $\mathrm{km}$ thick. Irregularities due to the field of the earth's crust (anomaly), which usually only exceed a few nanotesla values of the main field are more important when measurements are made on the surface of the earth. The anomalies are caused by differences 
in the magnetic properties of the geological formations and are therefore of interest for deposit investigations. These can rarely have values comparable to those of the main field, in a survey on the ground. Low and medium anomalies are constant in the field.

\subsubsection{The magnetic field period of the Earth's crust}

Since the temporal variations of the magnetic field are, for the most part, irregular, it is difficult to compare the results obtained in different field stations at different times. The magnetic surveys are usually done at a time when sunspots are minimal because the variations overtime are the weakest.

\section{3..1.4. Field and determination of anomalies}

As described previously, the terrestrial magnetic field corresponds to the superposition of two particular fields:

- A regular field or normal field, whose intensity is of the order of a few tens of thousands of nanotesla, wavelength greater than a thousand kilometers, and whose source is located at the Earth's core;

- A local anomalous field, whose intensity can reach a few thousand nanotesla, wavelength generally less than a hundred kilometers and generated by the presence of rocks with variable magnetizations in the earth's crust.

The magnetic anomalies are determined from the local field and therefore need to approximate the intensity of the field of deep origin to this end, a universal model, called IGRF or International Geomagnetism Reference Field, was adopted by the International Scientific Community in 1960. This model corresponds to a development in spherical harmonics, of which the first order (three terms) represents the dipole field, and whose higher order terms the non-dipolar field.

\subsubsection{Properties of magnetic substitutes}

The magnetic field is described by the equation: $B=\mu_{0} H+\mu_{0} J$, B is the magnetic induction (in $\mathrm{T}$ ) ; $\mathrm{H}$ is the magnetic field intensity (A m-1) ; $\mathrm{J}$ the magnetic moment per unit volume and $\mu 0$ is the magnetic susceptibility. When a magnetic substance is placed in the presence of a field and then withdrawn, it retains a part of the magnetization previously induced, this magnetization is called the remanent magnetization. Table 1 below classifies some rocks according to their magnetic properties.

Table 1. Magnetic Susceptibility of Sedimentary Rocks

\begin{tabular}{|l|c|c|}
\hline \multicolumn{1}{|c|}{ Names } & Susceptibility Interval x 10 & Average \\
\hline Dolomite & $0-75$ & 10 \\
\hline Limestone & $2-280$ & 25 \\
\hline Sandstone & $0-1660$ & 30 \\
\hline Clay (Shales) & $5-1480$ & 50 \\
\hline $\begin{array}{l}\text { Other sedimentary } \\
\text { rocks }\end{array}$ & $0-4000$ & 75 \\
\hline
\end{tabular}

Table 2. Magnetic Susceptibility of Metamorphic Rocks

\begin{tabular}{|l|c|c|}
\hline \multicolumn{1}{|c|}{ Names } & $\begin{array}{c}\text { Susceptibility Interval x } \\
\mathbf{1 0}^{\mathbf{4}}\end{array}$ & Average \\
\hline Amphibole & & 60 \\
\hline Schist & $25-240$ & 120 \\
\hline Phyllite & & 130 \\
\hline Gneiss & $10-2000$ & \\
\hline Quartzite & $250-1400$ & 350 \\
\hline Serpentine & $0-3000$ & 500 \\
\hline Slate & $0-5800$ & 350 \\
\hline Other metamorphic rocks & & \\
\hline
\end{tabular}

Table 3. Magnetic Susceptibility of Igneous Rocks

\begin{tabular}{|l|c|c|}
\hline \multicolumn{1}{|c|}{ Names } & $\begin{array}{c}\text { Susceptibility Interval x } \\
\mathbf{1 0}^{\mathbf{4}}\end{array}$ & Average \\
\hline Granite & $0-4000$ & 200 \\
\hline Rhyolite & $20-3000$ & \\
\hline Dolerite & $100-3000$ & 1400 \\
\hline Augite-Syenite & $2700-3600$ & \\
\hline Olivine-Diabase & $80-13000$ & 2000 \\
\hline Diabase & $20-16700$ & 4500 \\
\hline Porphyry & $80-7200$ & 5000 \\
\hline Gabbro & $20-14500$ & 6000 \\
\hline Basalt & $50-10000$ & 6000 \\
\hline Diorite & & 7000 \\
\hline
\end{tabular}


International Journal of Advances in Scientific Research and Engineering (ijasre), Vol 6 (2), February-2020

\begin{tabular}{|l|c|c|}
\hline Pyroxenite & & 10500 \\
\hline Peridotite & $7600-15600$ & 13000 \\
\hline Andesite & & 13500 \\
\hline Other acidic igneous rocks & $3-6530$ & 650 \\
\hline Other basic igneous rocks & $44-9710$ & 2600 \\
\hline
\end{tabular}

\subsection{Material used}

The processing and interpretation of the data used in this research was made possible by the use of the computer equipped with the following software: ArcGis; Origin Pro16 and Golden Surfer 13.

\section{ANALYSIS AND DATA PROCESSING}

An airborne survey was carried out by the firm CGG in collaboration with the National Hydrocarbons Company of Congo, (SONAHYDROC) and the Congolese ministry having the hydrocarbons in its attributions of 1973 to 1987. The aim of this campaign was to promote this sedimentary basin which has several seeps through its surface. The flight plan consisted of NorthSouth lines spaced $25 \mathrm{~km}$ and East-West crossings made every $18 \mathrm{~km}$.

But, in the territories of Oshwe and Northern Idiofa this spacing was reduced by half, so it went from $18 \mathrm{~km}$ to $9 \mathrm{~km}$; this was done to highlight the oozing found in this area. The distance between two stations near the recording is about $78 \mathrm{~m}$. This campaign provides a satisfactory coverage of the study area with a base of 291782 data. The survey has 121 crossing of profiles (Figure 2).

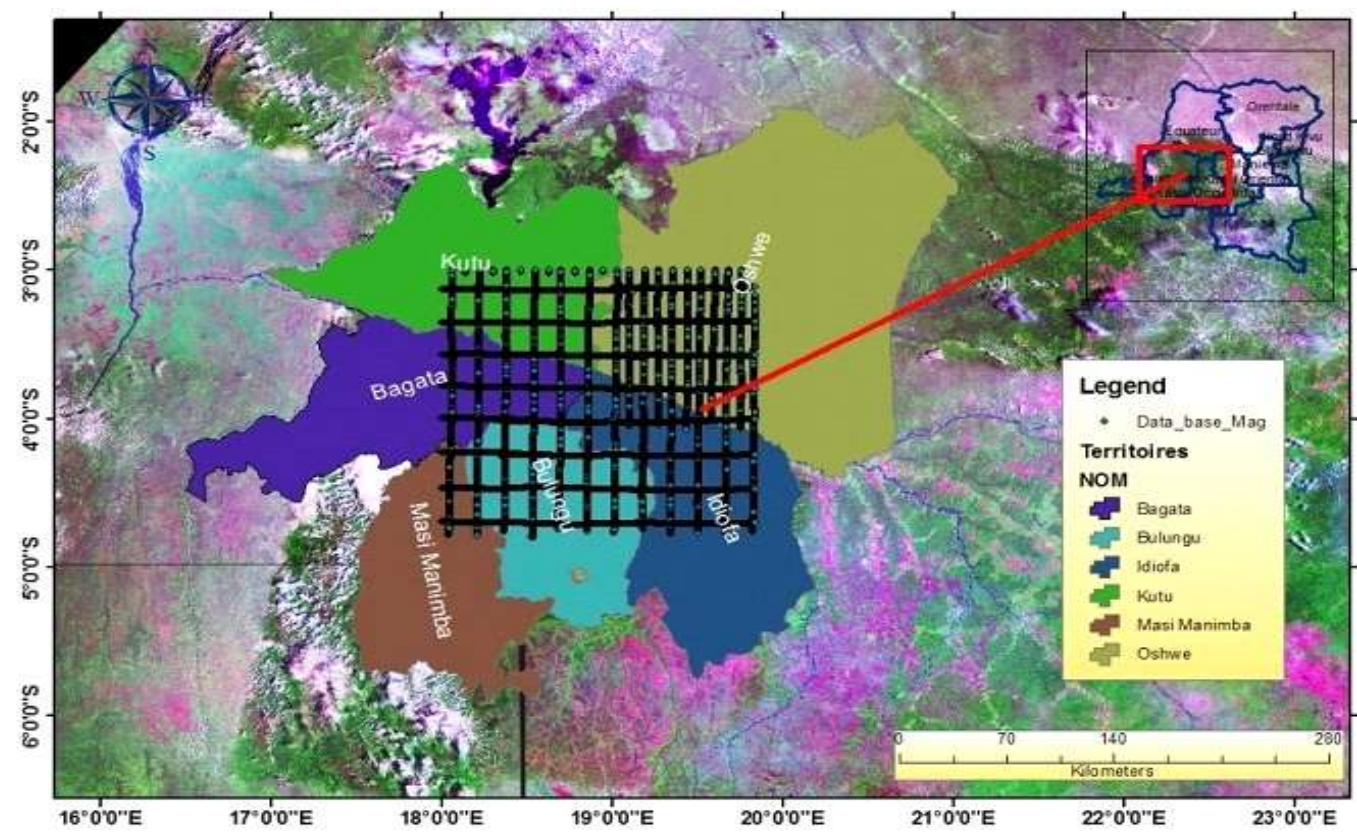

Figure 2. Design of the magnetic survey of the study area.

\subsection{Filtering the background noise}

There are signals recorded during the survey but not desired by the operator. These signals are called "background noise". This is the case of signals related to the presence of industrial installations or signals emanating from errors in the execution or correction of measurements. Therefore, the filtering will improve the ratio "desired signal/background noise". We generally recognize a background noise by its high frequency within the data set. on a profile the latter shows random jumps reflecting a kind of discontinuities (Figure 3). 


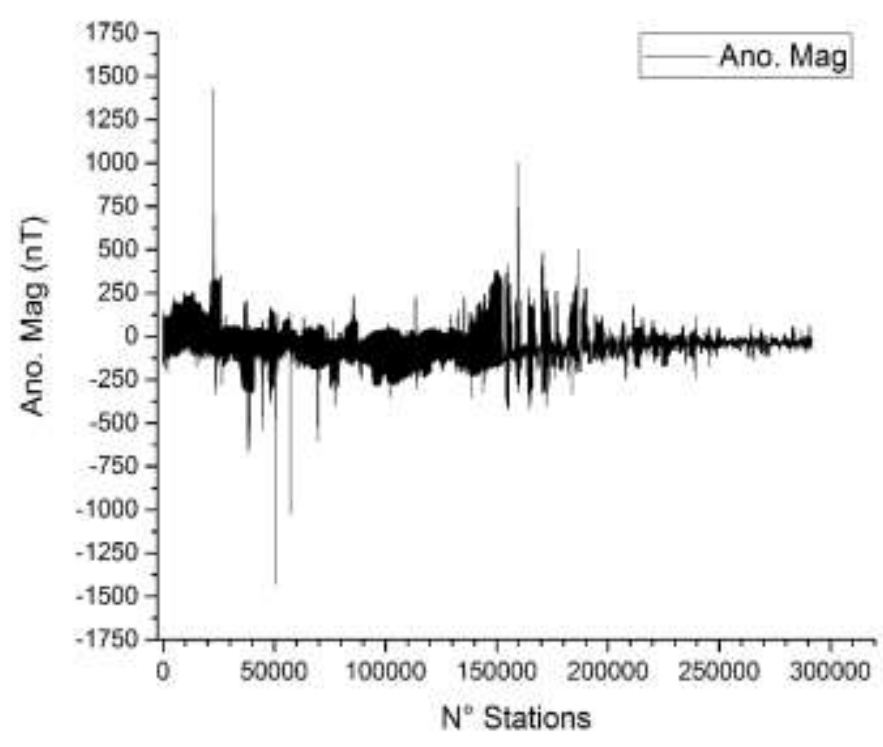

Figure 3. Figure 3: data profile before background noise filtering
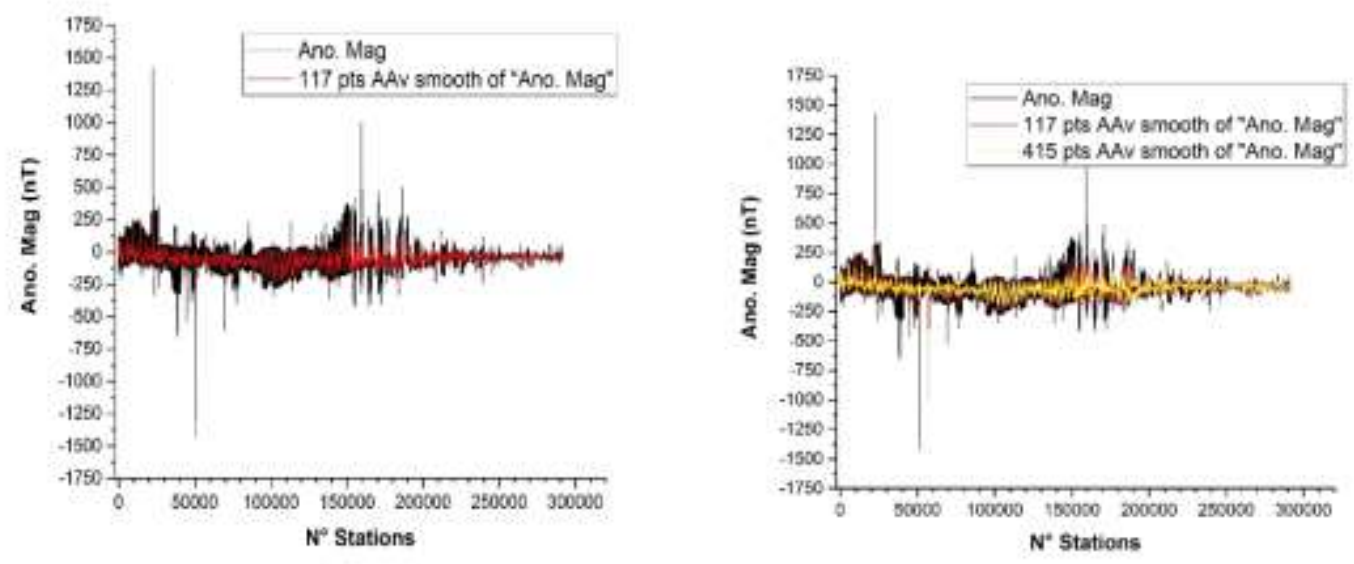

Figure 4. a) filtering with the windows of 117 points; b) filtering with the windows of 415 points

By observing these profiles, on the left the back color shows the unfiltered data with 117 points; on the right is the profile of the same data whose yellow curve shows noise filtering with 415 points.

\subsection{Separation of anomaly fields}

The anomalies obtained after a magnetic survey campaign are generally the reflection of the phenomena of the geological bodies located at different depths. There are anomalies which are caused by bodies located at very great depths like the crystalline basement (these are regional anomalies) and anomalies and that are caused by bodies located near the surface of the ground (these are residual anomalies). To facilitate the interpretation of the data, the resolution is then to separate the different fields of anomalies [2]. The usual methods of separating anomalies use low-pass and high-pass filtering. The low-pass filters eliminate the high frequencies of the total signal and lead to increasingly smooth line-contours of iso-anomalies. These kinds of filters therefore give smoother contour maps than those of the total signal. High-pass filters remove depth effects and enhance superficial or local effects. 


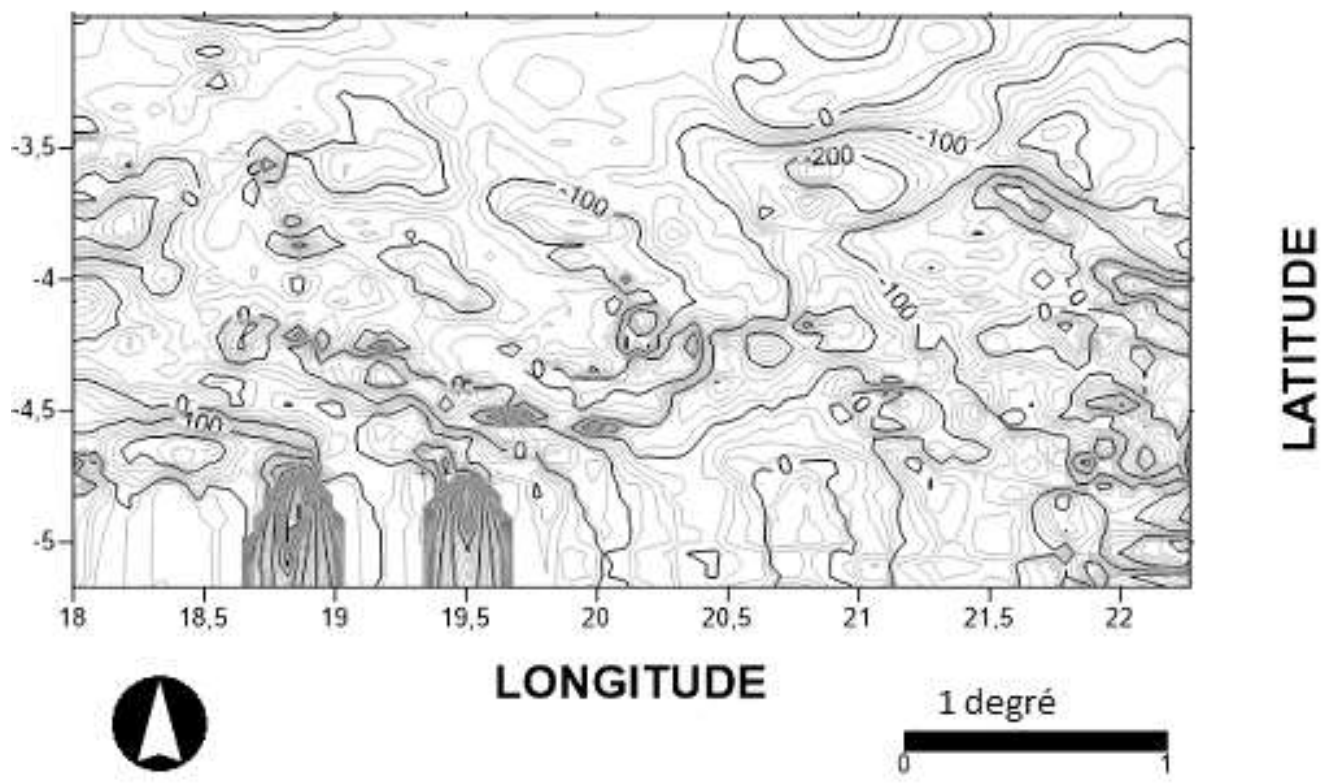

Figure 5. Contour map of iso-anomalies of the total magnetic field.

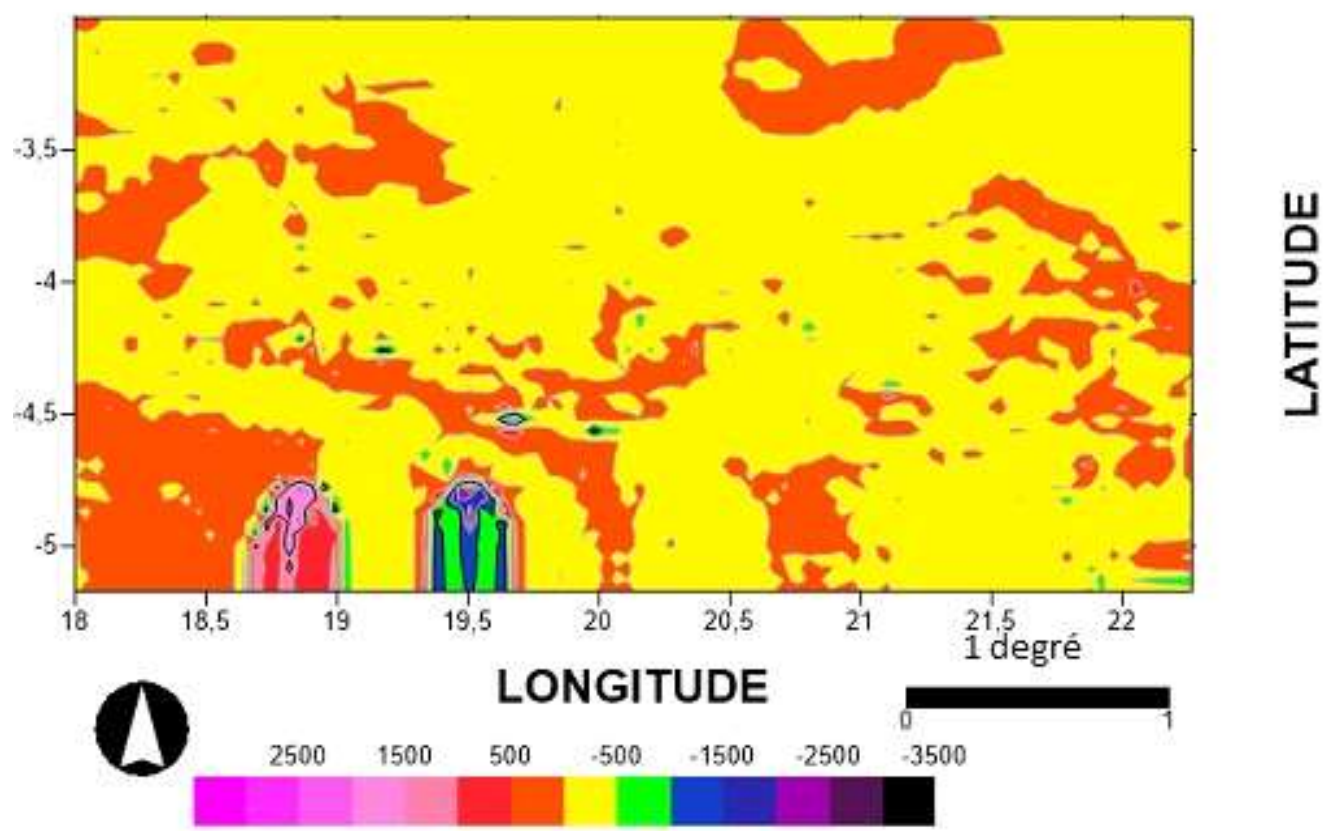

Figure 6. Color map of the total magnetic field of the study area.

Remember that, the low-pass and high-pass filters are convolution operations. The convolution of two real or complex functions $\mathrm{f}$ and $\mathrm{g}$, is another function, which is generally noted $f x g$ and which is defined by: $(f \times g)(x)=\int_{-\infty}^{+\infty} f(x-t) \cdot g(t) d t=$ $\int_{-\infty}^{+\infty} f(t) \cdot g(x-t) d t$. Or again, for sequels (we can talk about the use of the counting measure): $(f \mathrm{x} g)(n)=\sum_{m=-\infty}^{\infty} f(n-$ $m) \cdot g(m)=\sum_{m=-\infty}^{\infty} f(m) \cdot g(n-m)$. Then, we consider this formula as a generalization of idea of the moving average [3]. Complete or partial superposition sometimes complicates the identification of sources and their interpretations. Outside background noise filtering; the separation of fields in regional field and residual field is also one of the goals pursued by the processing of magnetic data. What we really want is to map the regional anomaly field and map the field of residual or local anomalies. thus, based on this method of regional-residual separation, we have developed maps of regional and residual anomalies of our study area (Figure 7). 


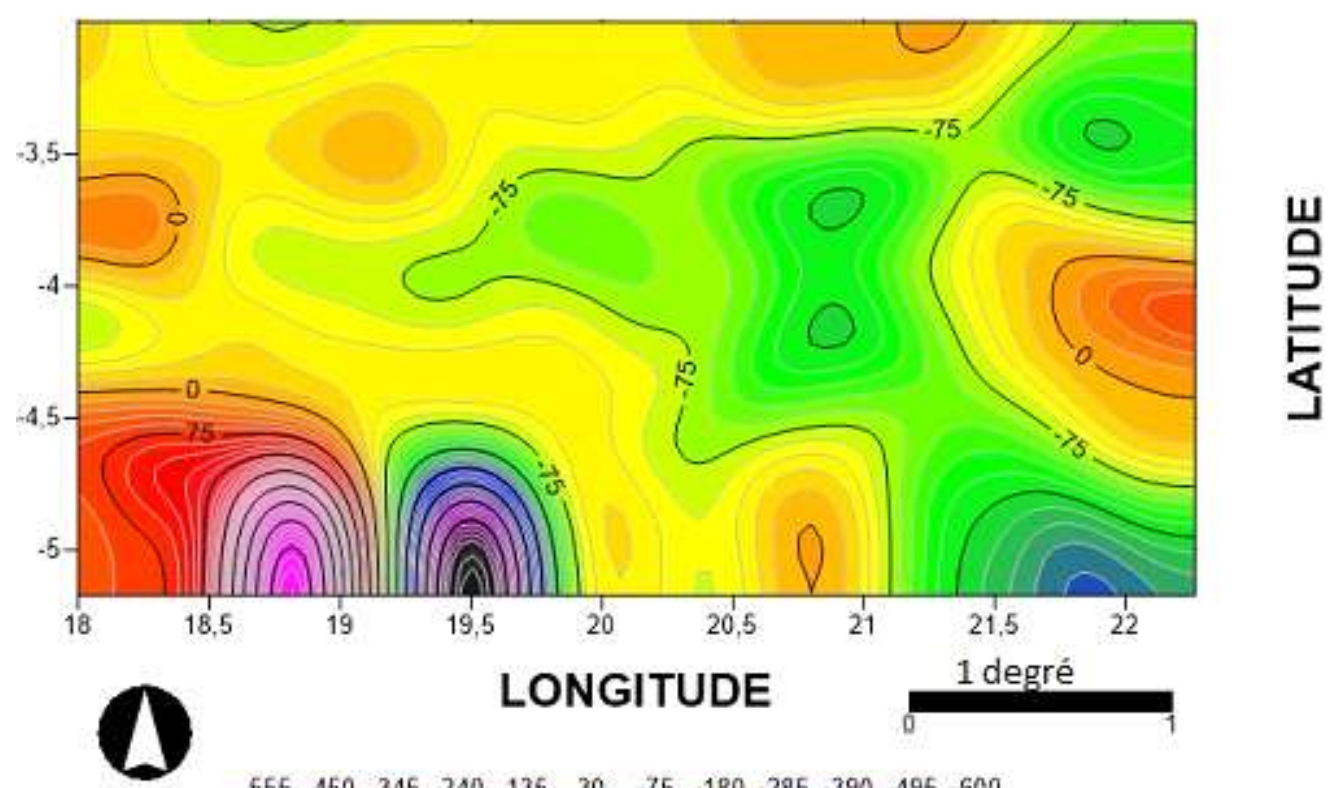

$\begin{array}{llllllllllll}555 & 450 & 345 & 240 & 135 & 30 & -75 & -180 & -285 & -390 & -495 & -600\end{array}$

Figure 7. 2D composite map of the regional magnetic field after low-pass filtering.

\subsection{Anomaly enhancement and interpretation}

In interpreting magnetic anomaly maps, one of the goals is to identify magnetic fracture zones and magma intrusions in the form of magnetic dipoles [4]. In our case, we will try to show the fractures likely to play the role of the setting up of the structural traps of our study area.

\subsubsection{Anomaly enhancement}

One of anomaly enhancement techniques in magnetic prospecting is directional filtering. It is the most effective method in detecting contacts between blocks of different magnetic susceptibilities and establishing their preferential direction. The confirmation of the geological and geophysical data. These directional filters calculate horizontal gradients of magnetic anomalies in directions chosen by the interpreter. Indeed, the anomaly above a vertical contact is materialized by a curve having a maximum on the side of low density rocks and a maximum on the side of high density rocks [5]. The point of inflection of the curve is directly above this contact, as we will see in the magnetic models. However, after calculating the horizontal gradient, this anomaly becomes a maximum, which facilitates the mapping of the contact. It should be noted that the maxima of horizontal gradients will be located vertically above contacts or faults such that on both sides, exists density [6].
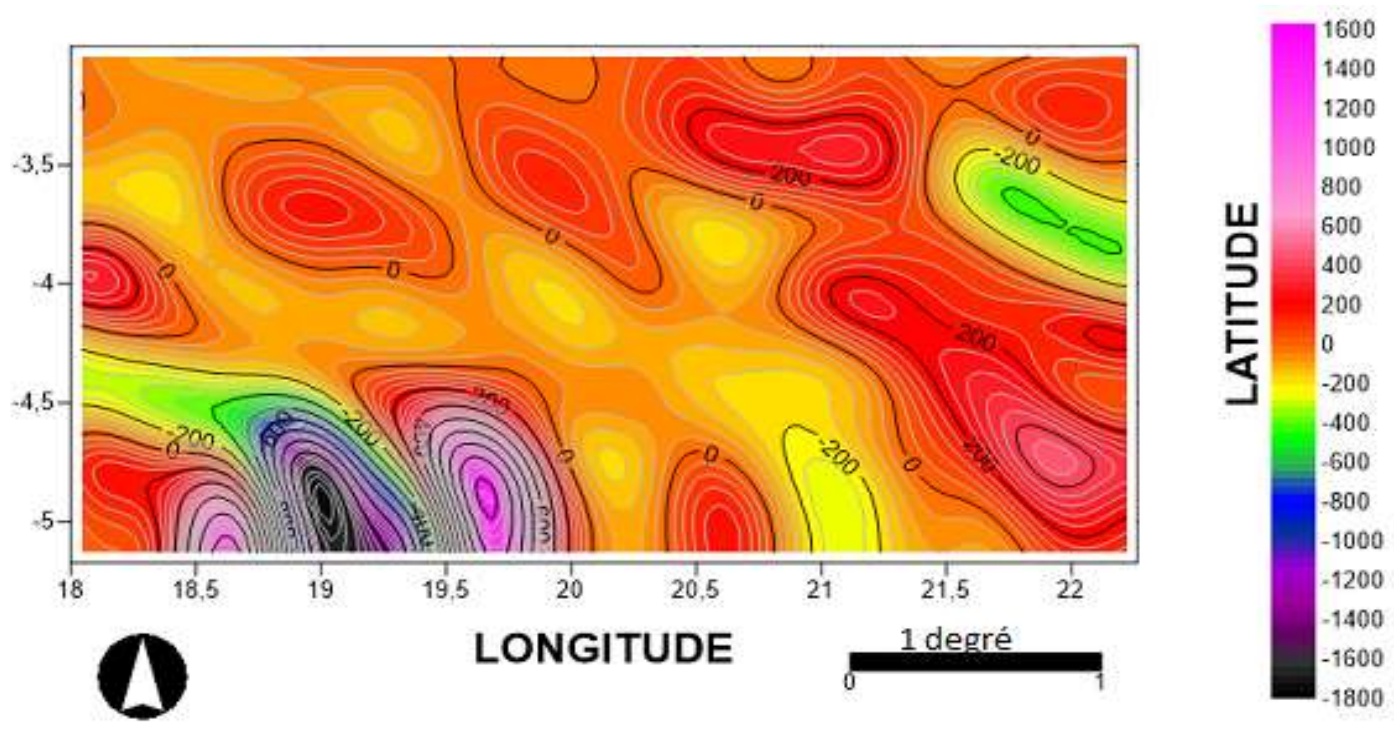

Figure 8. 2D composite map of the regional magnetic field after directional filtering North-East and south-west. 


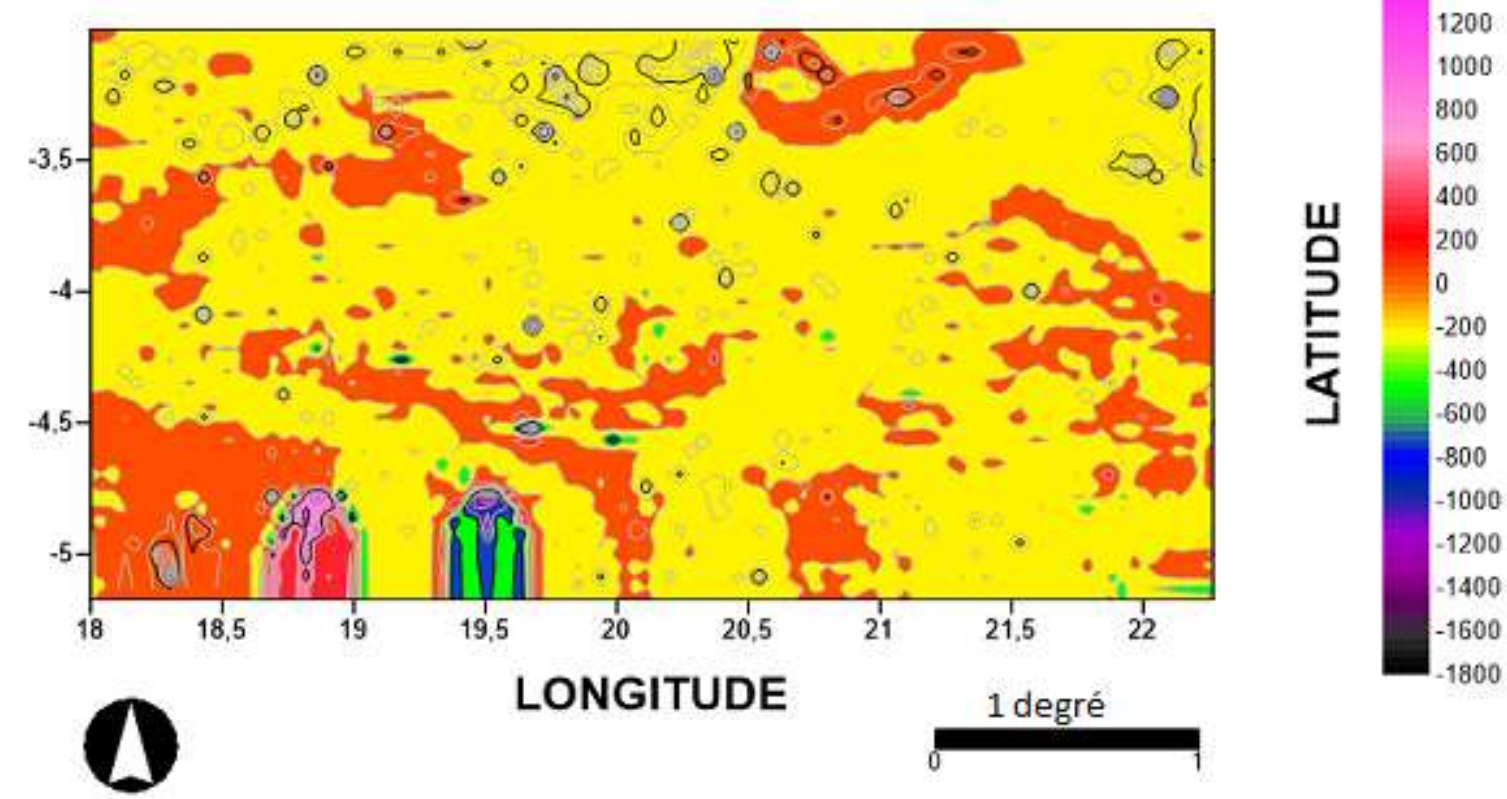

Figure 9. 2D map of the residual magnetic field after directional filtering North-East and south-west

\subsubsection{Interpretation of anomalies}

Baranov (1960) rightly states that applied geophysics is an art, guided by several sciences: physics, geology and mathematics. And later, Jacques [7] insists on the obligation for the geophysicist to behave as a physicist when he makes measurements and then as a geologist when he approaches the interpretation of the results or when he examines all of his deductions to finally be an informed mathematician to check his assumptions and justify his deductions. It is based on his idea that we approach a crucial stage of our work, which is that of the interpretation, therefore, to make speak the images that we obtained after analysis and treatment.

Magnetic anomaly maps are the basic documents for any interpretation in magnetic prospecting. The purpose for their interpretation is to find the distribution of sources distribution of magnetic susceptibilities. However, in the interpretation of maps, the identification of magnetic signatures is the first thing one does. On these maps, one looks for places that are actually the expression of the presence of interesting geological phenomena (lithological contacts, geological structures). The identification of magnetic signatures is usually based on the intensity of anomalies, the shapes of the iso-anomaly curves and magnetic profiles.

\subsection{Intensity of anomalies}

Maximum (heavy) anomalies and minimal (light) anomalies are usually distinguished, as are areas of constrictions of iso-anomaly curves that constitute higher gradient zones of the magnetic field. This type of identification absolutely requires that the magnetic card be provided with a scale of intensity of anomalies. It can also be distinguished high-dimensional maximum anomalies extending over tens of thousands of square kilometers, the intensity of which is sometimes very important: tens and hundreds of nano-tesla (regional anomalies). On a background of configuration and different intensity.

Looking at the magnetic map of our study area in figure 9 above, it should be noted that the south-west is dominated by maximum anomalies of the whole region (from 0 to $1600 \mathrm{nT}$ ), but also the presence of the only minimal anomaly (between -1600 nT and $800 \mathrm{nT}$ ). In addition, the rest of the area has more of less moderate anomalies moving slightly towards the heavy anomalies, except in the North-East where we find an anomaly evolving towards the slight anomalies (between $-280 \mathrm{nT}$ and $-580 \mathrm{nT}$ ): the area in green color.

\subsection{Shapes of iso-anomaly contours}

The examination of a magnetic card shows that it is possible to determine at first order several classes of anomalies. These are linear anomalies and circular anomalies. There are also other trends such as the extension of iso-anomaly curves in a preferential direction, the alignment of minimum or maximum values and discontinuities in the regularity of these values. Looking at the same magnetic map of our study area (figure 9), we find that most anomalies are more or less circular and/or ellipsoidal. Some linear 
anomalies are also visible on this map and show a trend of elongation in the North-West and South-East direction. However, several zones have constrictions of iso-anomaly contours. This situation is the expression of the presence of a very high gradient of the magnetic field towards the south-west; vest East and West of our study area.

\subsection{Magnetic profiles}

Profile tracing is also an essential step in the interpretation of magnetic anomaly maps. These profiles expressing the variation of the anomalies as a function of the distance are very important in the follow-up of the magnetic signatures of several structural models. To correctly interpret the linear anomalies, we have drawn a profile intersecting perpendicularly the structures of southwest (figure 10), west and North-west (figure 11) of our study area. The model that we found is a section that extends on both sides of the structure. For anomalies of circular shape, it is imperative to make a modelling, a three dimensional interpretation (figure 12), [6]. It should be noted that the magnetic profile provides information on the nature of geological structures and the depth of sources of anomalies. In the case of the fault, we observe a very high gradient of the magnetic field, in the case of a fold, the profile shows a symmetry. As for the founder of the sources of anomalies, the flanks of the anomalies are abrupt for sources close to the surface and flared for deep sources.

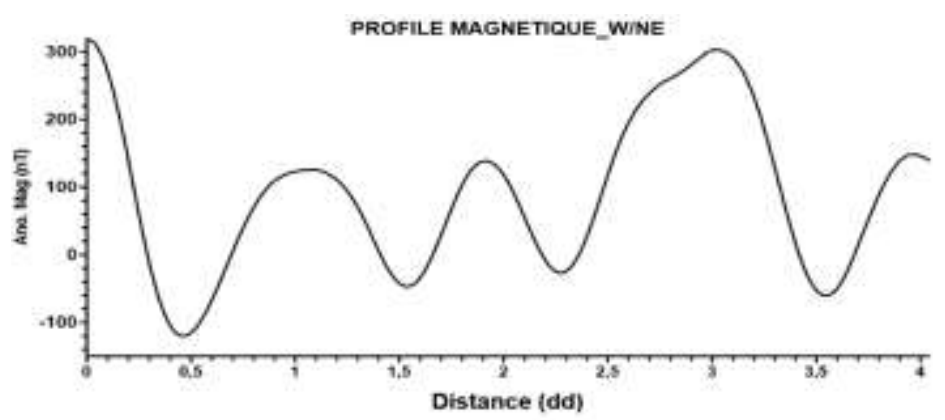

Figure 10. Magnetic anomaly profile in the west and North-East direction of our study area.

On this profile, we observe a very high gradient of the magnetic field of steep form between 0 and 0,5 degrees resulting in the contact of geological bodies of different nature located near the surface and/or the presence of faults at this location. The remainder of the profile shows alternating areas of high and low magnetic susceptibility as in the case of magnetic dipoles with flanks little flared. This shows that the geological bodies which are at the base of the anomalies observed are not superficial.

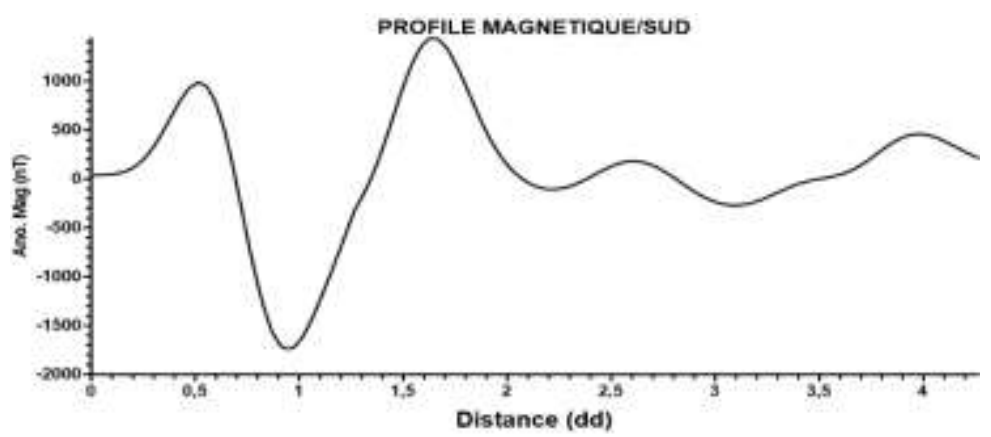

Figure 11. Profile of magnetic anomalies in the South direction of our study area.

A magnetic dipole is observed on this profile with steep sides with very high gradients. At this point there is the possibility of encountering faults. The rest of this profile shows a very flanked flank and informs us that the sources of anomalies would be very deep. 


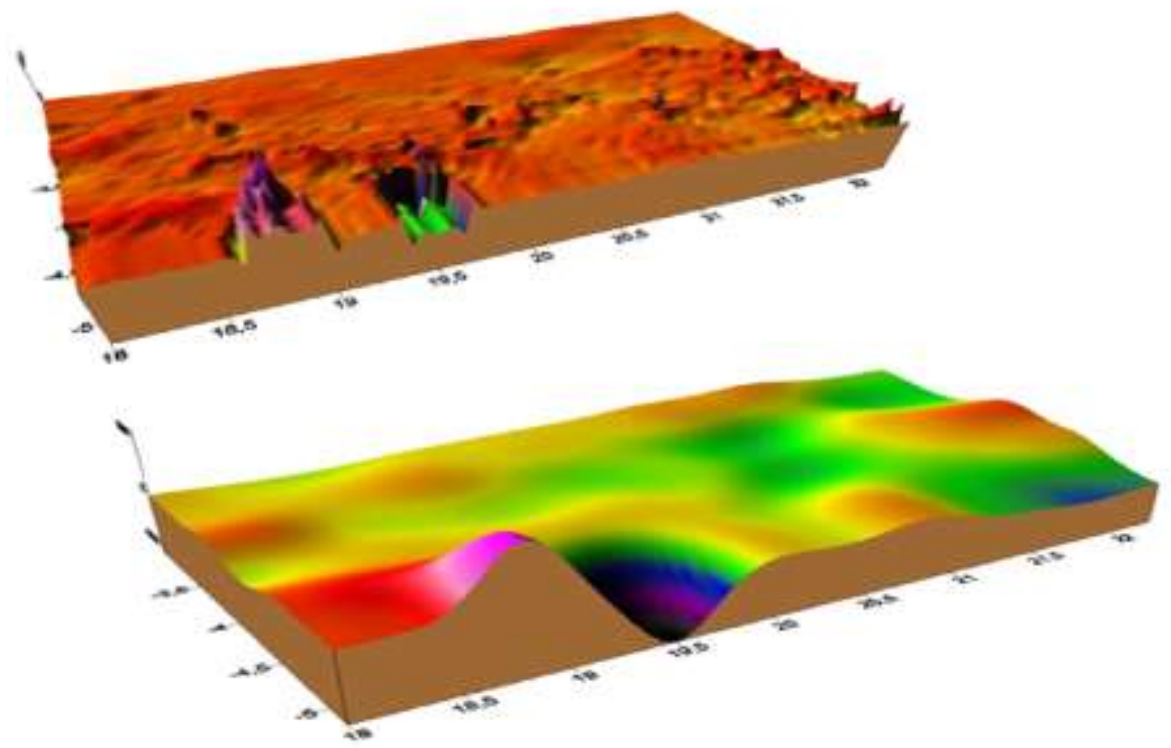

Figure 12. A: 3D image of the residual field; B: 3D image of the regional field.

\section{MODELING GEOLOGICAL STRUCTURES OF THE STUDY AREA}

To answer the main objective of this work, the elaboration of a structural model in relation with the petroleum sector of our study (figure 13) provide very necessary. Based on the results obtained, the structural model shows the existence of several ditches probably corresponding to the maturation areas of the source rocks and therefore the areas where the hydrocarbons in this sector would have been generated. This model also indicates the presence of shallows (domes) associated with anti-form structures and some with faults. These structures would be the main oil traps that can be encountered in this sector.

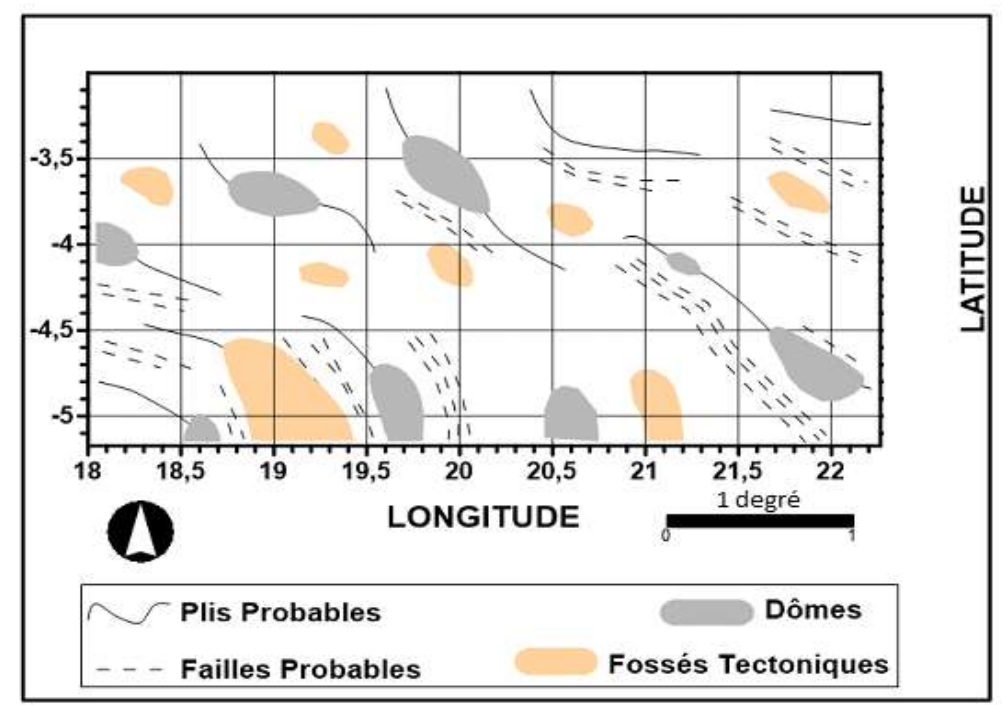

Figure 13. structural model of our study area.

\section{CONCLUSION}

In our work, we are interested in the southern part of the central basin where we have shown the spatial distribution of magnetic data obtained from the airborne campaign. This work focused on the analysis of the geographical and geological context of the Central Basin in a general way and in particular of its southern part, around Mai-Ndombe and Kwilu. We also talked about the magnetic prospecting method in general and how to detect the geological structures starting from the analysis of the crystalline basement. Thus, after background filtering and anomaly separation, we applied directional filtering to the regional field in order to enhance the lateral variations of this field. This last operation led to the highlighting of the various faults represented on the schema of the structural model of our study area. Aside from these faults, domes and ditches have also been highlighted. The 
interest of the results obtained is based on the fact that presence of faults and domes in this sector could be potential oil traps while the ditches would be the maturation zones of source rocks. The subsequent seismic, geological and geochemical studies will allow us to refine our results to enhance this area which is potentially rich in hydrocarbons.

\section{ACKNOWLEDGMENT}

We would like to thank the Congolese Hydrocarbon Company and the Congolese Ministry of Hydrocarbons for providing us with the magnetic data that we have used in this paper. We also thank the faculty of Oil, Gas and New Energies of the University of Kinshasa for having made available to us its data processing laboratory, remote sensing, Gis and Digital mapping.

\section{REFERENCES}

[1] G. a. Abrikossov, Geology du Petrole (Generalites, Prospection et Exploration), Moscou: Mir, 1982.

[2] F. Moreau, Methodes de traitement des donnees geophysiques par transformee en ondelette; these de doctorat presente a l'universite de Rennes I:, Rennes, 1995.

[3] N. Piskounov, Calcul differentiel et integral et theoreme de convolution, Moscou: Mir, 1993.

[4] J. D. a. P. Geoph, Rapport sur interpretation des leves aeroportes gravimetrique et magnetiques effectues par UTS Geophysics 2009 sur les blocs 17 \& 25, 2012.

[5] N. E. Goumi, Apport de la gravimetrie a l etude de la structure du bassin du Haouz, Maroc, 2010.

[6] Dubois et M. D. e. J. Cogne, Geophysique (Cours et exercices corriges), Paris: Ed. Dunod, 2011.

[7] S. Jacques, Gravimetrie appliquee aux recherches structurales et a la prospection petroliere et miniere, Paris: Technip, 1975. 